\title{
Adolescents' Positive Future Orientation as a Remedy for Substance Abuse: An Ecosystemic View
}

\author{
Matjhabedi E. Mazibuko \\ Vaal University of Technology \\ Private Bag X021, Vanderbij/park, 1911, South Africa \\ chabi.mazibuko@gmail.com \\ Lloyd D.N. Tlale \\ University of South Africa \\ PO Box 392, Pretoria 0003, South Africa \\ tlaleldn@unisa.ac.za
}

\section{Doi:10.5901/mjss.2014.v5n2p69}

\begin{abstract}
The use of substance interferes with adolescents' ability to focus on their future, to delay fulfillment and to be goal directed. It is important to understand why some adolescents, who are at the same developmental stage and are affected by the same psychosocial factors, such as impoverished urban environments, tend to avoid negative outcomes, whereas others are at an increased risk from a number of psychosocial outcomes, including psychological distress, substance abuse, delinquency, teenage pregnancy and failure to complete high school. To achieve this understanding one has to consider the circular causal factors that impact on the adolescents' future oriented behaviour. The crucial question is what could be holding the youngsters back from goal oriented behaviour? What stops them from planning for a positive future? In trying to break into this web, the researcher decided to assume an ecosystemic perspective. In this paper, the ecosystemic perspective acts as an explanatory framework that refers to personal as well as social life in general. The values, understanding and actions of individual person are hard to understand if they are separated from the social context in which they occur (Engelbrecht, Green, Naicker and Engelbrecht, 1994:4).
\end{abstract}

Keywords: Adolescent; Future orientation; substance abuse; ecosystemic view; counselling.

\section{Introduction}

Future orientation is determined by normative life events and the developmental tasks that accompany those life events (Nurmi, 2005). In support of this view Nurmi (2005) and Seginer (2009) indicate that the thematic content of adolescent's future orientation pertains to specific life events within the domains of education, occupation, family, friendship and material well-being (Nurmi, 2005:47; Seginer, 2009).

As noted by Romero (2013) and reiterated by Little (2007) future orientation appears to be most important during transitional developmental periods, such as early adolescence. For at-risk children, early adolescence can be a turning point in the life path. At this stage, adolescents are beginning to make important choices about peer groups, experimentation with drugs or sex and the importance of academic achievement (Crockett, Carlo, Wolff \& Hope, 2011). The ability to look ahead to the future, to understand how current behaviour relates to future goals, and foresee the consequences of behaviour are essential to navigating this developmental stage successfully. Thus future orientation is likely to be a particularly important protective factor for youth approaching the transition to early adolescence (Crockett, Carlo, Wolff \& Hope, 2011).

Sica (2009) supports this view by indicating that future orientation plays an important role as a protective factor in promoting resilience for youth facing adversities related to low socio-economic status. Thinking about the future or having a positive future orientation is related to enriched socio-emotional development and school adjustment for children living in poverty.

Nurmi (2005:4) defines future orientation as "the human ability to anticipate future events, give them personal meaning, and operate with them mentally". Future orientation can be thought of as a collection of schemata, or attitudes and assumptions based on previous experiences that interact with incoming information from the individual's 
environment to form expectations for the future, set goals and aspirations, and give personal meaning, then direct future oriented behaviour such as delay of gratification, planning, and achievement oriented behaviours.

\section{Literature Review}

Adolescent who are future oriented are strongly motivated to succeed, they show initiative and carry out plans related to future fulfilment of activities and are willing to be involved with new and interesting activities over a long period of time (Tabachnik, Miller \& Relyea, 2008). Future orientation functions as an integrating link between achievement motivation and career striving. Individuals are characterised as highly future oriented if they expect or believe that immediate performance or improvement of skills and knowledge are highly important in achieving personal future goals. The importance of the present activity is high because it is perceived to be contingent upon success, to earn the opportunity to advance (Husman \& Shell, 2008).

\subsection{Exploring a Future Oriented Adolescent}

Horstmanshof and Zimitat (2007) maintain that future oriented individuals may be expected to seek relatively permanent relationships. In contrast, individuals who are less future oriented are not expected to willingly seek permanent relationships and they may enjoy temporary relationships. Thus future oriented adolescents are expected to be more careful in starting relationships and in their ongoing relationships. They do not easily start new relationships; they are more cautious and selective in initiating relationships.

Closely linked to the above is the onset of intimate relationships amongst adolescents. Future oriented adolescents are found to delay their engagement intimate relationships and thus reduce the risks associated with early intimate relationships. Furthermore, teenagers and young adults with a strong future orientation tend to be less sexually experienced, to have fewer sexual partners and to use precautionary measures more effectively. They are also more likely to use a variety of methods to reduce AIDS risk, than their less future oriented counterparts (Husman \& Shell, 2008).

Zhang, Karabenick, Maruno and Laurermann (2011) state that future orientation is related to academic goal setting through the mediating effects of internalising, self-efficiency and locus of control. Adolescents with a high future orientation are motivated and perform better at school; they have significantly higher grades than their less future oriented counterparts. Vansteenkiste, Sierens, Soenens, Luyckx and Lens (2009) state that this is due to the fact that future oriented adolescents perceive their behaviours and successes as a result of their own interest and not effort of external urges and inducements.

In line with the above notion, Seginer (2009) asserts that adolescents with a positive future orientation are proud of themselves; they have a positive attitude toward life and strive to become role models to other youths.

\subsection{Adolescence as a Shaping Force}

Contrary to the prevailing belief that adolescence is a period of turmoil and rebelliousness, Craig (1996: 436) is of the opinion that adolescence is not necessarily a turbulent period, in fact, adolescents have positive relationships with their parents. The emotional turmoil that they experience is part of growing up and the conflict that may occur is because the adolescent has to make his/her own judgments and regulate own behaviour. To achieve independence the young adult has a task to re-evaluate rules, values and boundaries that they previously learned at home and at school. Furthermore, in this period the adolescent learns to be interdependent which a commitment to significant others.

In support of the above, Moshman (2009) asserts that adolescence is not a time of rebellion, crisis, pathology, and deviance. Adolescence is a time of decision making, a time of commitment, a time of carving out a place in the world. Manzi, Vignoles and Regalia (2010) refer to adolescence as the stage of identity versus role confusion. The author further purports that adolescence should be a period reserved for experimentation with various identities and ideologies, a period during which society encourages the young to experiment before committing themselves to an identity for the future.

Furthermore, Manzi, Vignoles and Regalia (2010) perceive adolescence as a period for acquiring a variety of developmental skills. Amongst these new skills is the development of a more sophisticated, realistic perspective on time. The primary task of adolescence is to overcome time diffusion, which is the childish notion, that one has all the time in the world or that one can just let time take care of things. Moshman (2009) argues that young people must come to 
realise that time is limited and that society expects them to adopt an identity by the end of adolescence.

Manzi, Vignoles and Regalia (2010) propose that the major psychosocial task linking childhood with adulthood involves developing a viable adult identity. Identity formation according to Daviss and Diler (2012) does not happen neatly and it usually does not happen cataclysmically. It involves commitment to a vocational direction, an ideological stance and a sexual orientation.

According to Crockett, Carlo, Wolff and Hope (2011) one of the primary developmental tasks of adolescence is the exploration and formation of a vocational identity. The economic status of the adolescent's parents plays an important role in shaping the adolescent's vocational identity. Parents who experience economic stress are more pessimistic about their lives and the future of their children, and are less likely to encourage tertiary attendance. These parental beliefs and behaviours may dampen children's expectations and job aspirations and reduce their sense of hope about the future. From this perspective, Cano, Castillo, Davis, López-Arenas, Vaquero, Thompson and Saldivar (2012) assert that one aspect of the damage that results from parental unemployment is that it denies a child a positive role model of who may help in his or her search for a vocational identity.

One other task that the adolescent is faced with is identity formation. Kuhn (2008) is of the opinion that the acquisition of formal operations, which occurs during middle to late adolescence and includes advances to abstract thinking, enable the young adult to re-evaluate roles that were learnt. They accept some roles and reject others as a way of forming their own identity. They use references groups to re-evaluate roles and as such copy those behaviours that they find acceptable and can be integrated in their personal identity and others which may be discovered. Some adolescents commit to roles as determined by their parents or significant others. To these adolescents transition to adulthood is smooth. Others avoid making any decision and these young adults lack direction (Kuhn, 2008).

According to Marcia (1993) the adolescent may adopt four different types of identities. With diffused identities we find that young people have not yet chosen any vocational or ideological direction, even though they may have experienced with various roles and ideologies. Identity diffused youngsters frequently resort to defence mechanisms as ways of coping with the anxieties associated with not having developed an identity. From this view, continually being consumed by the latest fad or continually seeking immediate pleasure (as in the case of substance abusing adolescents) can be manifestations of an identity diffused adolescent's sense of meaninglessness, hence lack of future orientation.

Similar to identity-diffused youth, Marcia (1993) contends that adolescents in the moratorium identity status are currently struggling with their identities. The moratorium youth's lack of defined goals or clear values and direction contributes to feelings of anxiety. Marcia (1993) also suggests that these children have ambivalent relationships with their parents in that, while struggling to liberate themselves from their mothers, they are having difficulties resolving their oedipal conflicts.

In contrast to identity or moratorium youths, Marcia (1993) points out that an adolescent with a foreclosed identity has adopted an identity and a system of clearly defined values. According to this view these adolescents have prematurely endorsed the view points of their parents and society's other authorities in lieu of examining alternative roles and values. The fourth type of identity status for adolescents is achieved identity. Individuals with an achieved identity have experienced the confusion and uncertainties that accompany experimentation with different identities and ideologies during adolescence. As a consequence of their struggles and experimentation, however these individuals emerge from adolescence with an independently formulated identity with regard to vocational, personal, and ideological issues (Marcia, 1993).

\subsection{Reasons for Adolescents' Predisposition to Substance Abuse}

Crockett, Carlo, Wolff and Hope (2011) indicate that adolescents do not make up a homogenous group. The majority of them negotiate the lengthy path to adult maturity successfully, but a large number do not. Furthermore, Crockett, Carlo, Wolff and Hope (2011) suggest that ethnic, cultural, gender, socioeconomic, age and lifestyle differences influence the actual life trajectory of every adolescent. At the same time Kuhn (2008) asserts that adolescents do not experience an improvement in health, largely as a result of dangers that include substance abuse, accidents, suicide, homicide, sexual diseases (including Aids), delinquency and emotional difficulties.

The environment, in which the adolescent grows up, plays an important role in his or her successful negotiation of the path to adulthood. Adolescents from impoverished communities manifest an appreciably more restricted orientation to future events. They are therefore at an increased risk of being negatively affected by this stage. The South African situation as reflected by Donald, Lazarus and Lolwana (2010) poses a greater challenge to adolescents. Poverty is widespread in South Africa and that children are left without proper guidance or supervision because parents have to 
work long hours away from home. Under such conditions adolescents become vulnerable and powerless against substance abuse and their existence revolves around survival.

\subsubsection{Sense of self}

One of the adolescent's tasks is a normative task of forging an identity that is based on the need to differentiate the self vis-à-vis the various roles that they play in life. They have to develop a different self in relation to his parents, friends, people with whom they are romantically involved, teachers and the like. The challenge presented by such role differentiation is to simultaneously consolidate these multiple selves into a coherent, integrated identity (Hamman, Gosselin, Romano and Bunuan, 2010). The search for identity, the need to find out who one is and what one would like to accomplish in life, depends largely on what the environment has to offer.

According to Manzi, Vignoles and Regalia (2010) young people display anxious conformity to their peers because of the new identity and sense of belonging, which eases the apprehensions provoked by breaking away from the family? The adolescents are constantly exposed to two incompatible pressures: their parents and teachers as authority figures and their peer group as their reference group. According to Kuhn (2008) this is cross-pressure which is the term used in child development to refer to an adolescent who is subjected to opposing influences. For instance, parents teach and emphasize the value of hard work and staying clean from substance abuse, while peers put pressure on the youngster to experiment with drugs.

\subsubsection{Age segregation}

According to Wolman (1998:5) children are born helpless and depend on the care and protection given to them by their parents or other adults for survival. Adults are interdependent and their self-supporting activities necessitate interaction with other adults. Whereas adolescents are struggling to find where they actually belong, they have outgrow the need for continuous parental care, but they are not yet ready for sharing adult responsibilities. They do not want to be dependent on their parents, yet they are unable to take part in the interdependent system of adulthood. They rebel against childhood dependence but before they reach interdependence they crave independence and tend to be rebellious.

Adolescents experience age segregation because of the choices they make and also due to circumstances beyond their control; they tend to remain apart from both younger children and adults. Adolescents' separation from younger children deprives them of opportunities to guide and tutor those who are less knowledgeable than themselves. Their separation from the adult world means that they do not get a chance to learn their social responsibilities by working alongside experienced people in responsible positions (Kuhn, 2008).

\subsubsection{Economic dependence}

Kuhn (2008) refers to this period of adolescence as a process which is deeply affected by the social and economic times. This is because adolescents are highly sensitive to the society around them, its values, political and economic tensions and unwritten rules. The adolescents are in the process of forming plans and expectations about their own future, and their expectations will depend in part on the cultural and historical setting in which they live (Crockett, Carlo, Wolff and Hope, 2011).

In a fragile economic situation such as the one experienced in South Africa, technologically advanced jobs go to experienced and economically skilled adults. Adolescents therefore experience prolonged dependence on their parents and this situation increases their frustration and restlessness (Crockett, Carlo, Wolff and Hope, 2011). The economic situation in South Africa is not encouraging to the youngsters. To bring it closer home the youngsters in Vanderbijpark or in particular in the Sebokeng Township do not have much to look forward for, as far as the future is concerned. They live in an environment that is infested with unemployment, as major industries in the area such as Iscor have retrenched hundreds of its employees. Not only are factory workers affected by unemployment but also youngsters who have just graduated as teachers cannot be employed by the education system. The present situation as described affects the adolescents' future orientation as they do not have role models to look up. The impact of economic stress on children is important given that adolescents are entering the work world during a period of restricted opportunity, with implications for their future social-economic status. Anckarsäter, Lundström and Kollberg (2011) argue that confidence about his or her future and the economic order is a key to an adolescent's sense of hope about the future.

Hopefulness refers to the degree to which adolescents possess a comforting or life sustaining reality-based belief 
that a future exists for themselves and others (Kuhn, 2008).

\subsubsection{Global crisis affecting adolescents}

Adolescents are vulnerable and susceptible to crisis in their own country as well as distant crises reported live in the media. Kuhn (2008) asserts that adolescents and young adults are the ones who fight in wars and participate in riots and sustain movements of social reform. Furthermore, adolescents continue to be distressed by crises happening around them.

Another crisis that challenges the adolescent today is the HIVIAIDS epidemic. Leroux (1994:266) maintains that worldwide adolescents have been recognised as a high -risk group for HIV-infection. Some of the most important reasons for this are the early age at which adolescents become sexually active, and also that, as a group, adolescents tend to perceive themselves as physically and psychologically invincible.

\subsubsection{Mass media}

Individuals learn best when they can act on their environment, perceive the consequences of the actions and have some power to effect change. But there is no way to alter the events on television, radio, or the movie screen. Teenagers with their rapidly developing physical and cognitive capacities are vulnerable to the passive role of consumers of the mass media (Kuhn, 2008). Adolescents spend most of their time with peers watching movies or listening to the radio, they then learn casual acceptance of tragedy or brutality or develop a thirst for excessive raw stimulation (Kuhn, 2008).

\subsubsection{Adolescent's concern with body image}

According to Wolman (1998:63) the discrepancy between the speed of biological development and the speed of psychological development is the cause of a great many problems in adolescence, the rapid physical changes in adolescence often cause a great deal of anxiety. Wolman (1998:63) also suggests that adolescents are concerned with their looks and may feel embarrassed by a sudden increase in the size of their limbs or facial features, which seems out of proportion with the rest of the body. They compare themselves to their peers and worry whenever they notice that they are different from others.

Kuhn (2008) asserts that some young people subject themselves to intense dieting while others embark on rigorous regiments of physical fitness and strength training, weight lifting, athletics or dancing. The primary concern with boys is physical power that can be exerted on the environment, whereas girls worry about being too fat or too tall, they focus on weight in part because of their concern with social acceptance. For instance, adolescents in the study reported that smoking marijuana helps them to stay slim and gives them supremacy.

\subsubsection{Ambivalent feelings and inconsistency}

Adolescent's feelings are volatile, their actions inconsistent and rarely in harmony with their verbal interjections. Wolman (1998:68) indicates that adolescent inconsistency reaches its peak with parents. At one moment the parents are regarded in a highly idealised and glorified perspective and at another time they are believed to be tyrannical, unfair, and wretched creatures. They demand independence from their parents, but at the same time seem to prefer to be dependent on them as well. Wolman (1998:68) adds that the surge of new impulses and the decline in self-control frequently puts the adolescents in frustrating situations.

Another challenge facing the adolescents is feelings of ambivalence. They may feel depressed without any objective reason; they may suddenly feel weak, inadequate, and helpless and shortly thereafter burst with enthusiasm, energy and self-confidence. They often hate and adore the same things and the same people at the same time (Wolman, 1998:68). When adolescents start to smoke cigarettes, drink alcohol and take drugs, it is usually out of defiance of the adult society or an attempt to prove to peers that they are part of the group. At times it is to allay inner anxiety, to overcome feelings of inadequacy and inferiority and to cope with depression (Wolman, 1998).

\subsubsection{Anxiety}

Adolescents are prone to diffuse feelings of weakness associated with doubting their ability to cope with any danger or to 
withstand any stressful situation. They tend to underestimate their own resources and feel trapped by whatever adversities they may encounter (Wolman, 1998:69).

Hamman, Gosselin, Romano and Bunuan, (2010) asserts that adolescents are self-conscious, have low selfesteem, and tend to be critical of themselves. Some adolescents develop a gloomy outlook on their future, doubt their ability to face adult tasks and have suicidal thoughts. Wolman (1998: 69) adds that anxiety in adolescents is one of the symptoms of their feelings of inferiority. They wish to be adequate, mature, and self-sufficient adults, they wish to be totally independent. But since total independence imply isolation, this with never comes true. Many adolescents then feel inadequate and frustrated by their dependence and do not expect much of themselves since they view their dependence as failure.

\subsection{Ecosystemic View of Adolescents' Future Orientation}

Seginer (2009) asserts that reality is behaviour that is intimately dependent on the context in which it occurs. Nurmi (2005) support this view by pointing out that human experience and action cannot be properly understood if they are taken away from the context in which they occur. When psycho-educational problems arise, it is useful to examine the problem in the context of the family, peers, school and the community as a whole.

\subsubsection{The role of the family}

Under normal circumstances, fostering a future orientation begins during infancy, as the parent rehearses imminent developmental changes in the present, with the infant (Seginer, 2009). Parents and other family members influence future-orientation through a variety of mechanisms including modeling direct socialisation of future orientation, setting norms for achievement and communicating expectations (Nurmi, 2005). The family continues to play an important role in charting the child's future. The success of the parent in fostering orientation emerges in early adolescence when the youngsters display a more sophisticated capacity for future orientation. The process of orientation continues and extends to other important life domains such as education, family relationships and career.

The distance between family and educational institutions might prevent adolescents from negotiating and understanding institutional norms and transitions and might influence the content of their future orientation (Nurmi, 2005). When parents are actively involved in the adolescents' educational matters and show interest in their plans for the future as well as their goals aspirations, the youngsters become better prepared to plan and think about their future in a positive way. They become optimistic and realistic about their future career and are encouraged to feel that they have more control over their ability to reach their goals. On the contrary, lack of parental involvement in schools has an adverse influence on the adolescents' aspirations and hope that their goals for the future will be realised.

Daviss and Diler (2012) indicate that incompatible values between the family and educational institutions limit learner's educational aspirations. Traditional values such as Ubuntu and collectivism are at odds with the competitive and individualistic ethos of schools. This might cause adolescents to limit their educational aspirations. In families where traditional values are adhered to, where domestic responsibilities are assigned to females and occupational demands are placed on males, there will be less support for educational goals and this might influence adolescents to hold conflicting expectations for the future. In support of this view, Mcabe and Barnet (1999:230) indicate that cultural norms influence adolescents' expectations for the future by setting community standards for normative and desired developmental goals.

In a nutshell, the parents' beliefs and hopes for the future influence the way the adolescents perceive their future. Little (2007) acknowledges this fact and point out that girls are especially likely to reduce their aspirations on the basis of their father's pessimism about the future.

\subsubsection{The peers}

Daviss and Diler (2012) suggest that peers may also be important socialising agents for future orientation. They can influence goal commitment by conveying normative and inspiring competition. Agreeing publicly to strive for a goal can also enhance commitment relative to private agreement.

Wolman (1998:24) supports this view by pointing out that as members of a peer group, adolescents feel more selfconfident more courageous and more outgoing. Belonging to a group enhances adolescent's self-image. They feel that they have more to say as compared to single individuals. Peer pressure is a powerful motive for group identification and sharing the norms and values of peers. 
The kind of peers that the adolescent belong to, will determine the nature of future orientation for them. If the group's future orientation is detailed, optimistic and goal directed, then the adolescent will also hold optimistic views about the future. Adolescents who abuse substances will affiliate to a group that has similar habits, either to maintain the habit or to feel that they are not alone. This group of adolescents will more often paint a gloomy picture of the future and will not invest in the future.

More future oriented adolescents possess intentions to avoid substance abuse and also have more positive attitudes towards the future. These adolescents are more likely to inquire about the peer group before affiliating to it. They will also explore consequences of substance abuse and get more information on the substances offered by their peers. Lasane and Jones (1994:401) reported that less future oriented individuals place greater value on social relationships when making academic decisions even if the decision rendered by these social relationships compromised responsible academic decision making.

\subsubsection{The School}

The school as a socialising agent plays an important role in fostering future- orientation. This is where the adolescent learner is exposed to a wide range of career opportunities through career exploration, information about careers, jobs and the world of work (Lasane \& Jones, 1999:35)

Future orientation is related to academic goal setting, motivation and planning for the future. The school then sets the platform for adolescents to engage these processes. Depending on the nature of orientation within the adolescent, the processes will be of value in assisting him to chart his path to adulthood.

\subsubsection{The adolescent}

Future orientation happens not solely through external resources, but also through internal resources found within an individual. Thus hopes, fears and goals for the future can be found through both internal and external sources within an individuals' environment (Nurmi, 2005).

The developmental task of adolescents is a search for identity. Manzi, Vignoles and Regalia (2010) believe that it is during this search that the adolescent is pre-occupied with the possible self, which is represented by what he would like to become (i.e. hoped-for-self) and what he is afraid of becoming (i.e. feared self). The possible self that represent hoped-for-self includes the hopes, dreams and aspirations of the adolescent and contain images and visions of the adolescent in a desired end state. The hoped-for-self is domain specific and is critically important to behaviour because it houses not just abstract goals but also the specific scripts, strategies, plans and associated affect for the actualisation of a goal.

Manzi, Vignoles and Regalia (2010) theorise about the role of the future thinking in behaviour, incorporating the constructs of motivation, planning and evaluation within the family of possible selves. They built on those constructs to theorise an integrated relation between self-concept, motivation and behaviour.

Traditionally, self-concept has been defined as self-knowledge derived from an individual's past experiences and this concept (self-concept) has been equated with self-esteem. But currently self-concept is derived not only from past experiences but is also dynamically future oriented (Markus \& Nurius, 1996:954). I then claim that adolescents with a negative self-concept such as those who abuse substances will have a negative view of the future or they will have blocked future orientation. Markus \& Nurius (1996:954) noted that the future oriented components of the self are focused on future goals and desires and serve as the link between self-concept, motivation and behaviour.

As pointed out by Markus \& Nurius (1996:954) possible selves provide a three-fold explanation for understanding the mechanisms through which future orientation influences or motivates behaviour. Firstly, possible selves provide the context for the meaning the adolescent make of his own behaviour. The hopes and fears that they hold for the future become the standard by which they measure current behaviour or information. Secondly, there is a possible self's incentives for means-end behaviour. Here the adolescent seeks to achieve his hopes and dreams and strives to avoid fears. It is the balance between these possible selves that serves to motivate behaviour. Thirdly, the procedural knowledge of possible self regulates and guides behaviour in personally meaningful ways. Thus in facilitating meaning making, incentives for behaviour, regulation and possible selves function to dynamically organise and energise behaviour. It stands to reason then that balance in the achievement related to possible selves of adolescents has a positive effect on school persistence, avoidance of substance abuse and other negative behaviours and thus future orientation. However, an imbalance will have a negative effect resulting in a non-future oriented adolescent with no aim in 
life (Markus \& Nurius, 1996).

Nurmi (2005) and Seginer (2009) agree that optimistic and pessimistic strategies that adolescents employ in their academic as well as social life have an effect on their future orientation. Pessimistic strategies may facilitate short-term planning and task performance, but hinder the motivation to invest in the construction of a long-range future orientation. Norem and Cantor (1996) are of the opinion that pessimistic strategies arouse both the desire for success and fear of failure. An adolescent employing pessimistic strategy when facing an important event will engage in two presumably contradictory processes aimed at overcoming anxiety and maintaining high performance levels by setting their expectations at an unrealistically low level and mobilising himself by thinking about and planning for the upcoming event. For example, because of the adolescent's belief that using substances enhances performance, they will use substances when facing examinations to overcome anxiety, whereas at the same time this will have a negative outcome and hinder his investment in future orientation. In the similar manner, Seginer (2009) contends that adolescent employing optimistic strategies will set high performance expectations and avoid scenarios that entail negative outcomes.

One other attribute that influences or has an effect on future orientation is motivation. Research has shown that there is a correlation between future orientation and motivation, which includes positive academic outcome (Horstmanshof \& Zimitat, 2007; Kuhn, 2008; Cano, Castillo, Davis, López-Arenas, Vaquero, Thompson, \& Saldivar, 2012). Sheldon and Vansteenkiste 2005) reported that motivated youngsters who perceived a relationship between the present behaviour and future outcomes had higher outcomes than peers who lacked motivation and thus were less future oriented. Sica (2009) indicated that youngsters who were less able to extend cognitively into the future reported higher levels of test anxiety than those who did not. These are the youngsters who place greater value on present pleasures such as substance abuse and are thus less future-oriented.

\section{Research Methodology}

A qualitative research approach was adopted for the study. A qualitative research is an enquiry process of understanding a social or human problem based on building a complex, holistic picture, formed with words, reporting detailed views of informants and conducted in a natural setting (Creswell, 2010:06). The qualitative approach was preferred in this study because it allowed the researcher to explore adolescents' future orientation as a remedy for substance abuse' future orientation as a remedy for substance abuse. In this study, the researcher is interested in the meanings of the narratives of the adolescents and the qualitative approach will enable the researcher to remain committed to the viewpoints of the participants in order to understand what is influencing them the way they behave.

The age of the participants in this study was between fourteen and sixteen years. They were in the early stage of adolescence and were therefore experiencing extreme developmental changes. The fourteen year olds were mostly new at a secondary school and were pre-occupied with their formation of identity. The researcher infiltrated the worlds of these adolescents, interviewed and observed what was happening in their environment while they were behaving as naturally as possible, listening to the accounts and narratives of participants and constructing explanations of events.

The researcher adopted an interpretivist paradigm, which according to Benton and Craib (2011) is an alternative view to the positivist view of knowledge developed about social worlds as only obtainable objectively. The social worlds are not straightforwardly perceivable because they are constructed by each individual in a different way. It is different for each one of us, with words and events carrying different meanings in every case, and therefore they cannot be studied adequately using the methods of physics or chemistry. Interpretivism is interested in people and the way they behave and interrelate and in this case, adolescents.

\section{Findings and Discussions}

Participants in the study reflected an apparent lack of goal setting tendencies. They lacked motivation and the necessary commitment to their education. The most direct indication as to the level of motivation and commitment is the school attendance rate and beyond this the extent to which they are prepared to make an effort to come early to school. This is more evident in statements of one of the adolescents lamenting that:

"I think I will still be at school....But I think school is a waste of time. School stands in my way of doing things I like. I only go to schools because of my mother. It is a nightmare for me to think that in five years I will still be expected to go to school, when there are so many interesting things going on".

One participant went on and grumbled that 
"One other thing that discourages us to like school is that: You'll find that they (teachers) close the gate at 07:50. One teacher will see you approaching the gate and he won't care he will just lock the gate and turn away. He is concerned with his child's future. He is less bothered about our future. When he closes the gate we rejoice! We just go back and relax and smoke."

Another one indignantly added further that:

\begin{abstract}
"When they have (teachers) closed the gate we all contribute something from our pocket money. We can't go home because at home they expect us to be at school. We will then go somewhere where there are lots of trees and roll out our "zolo" (dagga cigar) and go back home at two o'clock".
\end{abstract}

This confirms the views held by Nurmi (2005:169) when he states that how adolescents see their future plays an important part in their identity formation, which is often defined in terms of exploration of goals and commitments to attaining those goals. In setting future oriented goals, exploring related options and making commitments, adolescents direct their own development in their social environment.

Nuttin (1984:95) suggest that within this future orientation framework young people set future orientated goals by comparing their present behaviour and their individual motives to their view of the future and their personal perceptions of future possibilities. Nurmi (2005:93) adds on to say these goals and hopes are then actualized by constructing different plans and strategies. The mentioned goal setting and goal orientated behaviour is found to be lacking in the adolescents with substace abuse problem, hence their decisions to stay out of school.

Horstmanshof and Zimitat (2007) suggest that people are likely to embrace a future orientation if they feel that highly valued goals are accessible to them. Likewise, the belief that a goal is beyond reach may restrict a person to a present orientation. Persistency depends both on the value of a goal and outlook for the future. In support of this view, Husman and Shell (2008) state that motivation is required in order to set goals and having knowledge upon which base future expectations is necessary. For example, adolescents who view their future as a replication of their parents' life may be motivated to establish goals that are different. Adolescents may have difficulty envisioning alternative outcomes without knowledge of these outcomes. In the case of adolescents in this study, it seems that lack of motivation, unfair enforcement of school policies and lack of commitment contribute to the adolescents' lack of goal directed behaviour.

\title{
5. Conclusion
}

The purpose of this paper was to explore the adolescents' future orientation as a remedy for substance abuse from an ecosystemic understanding. Substance abuse forms a barrier between the adolescent and the goal directed behaviour that the education tries to foster. The adolescent who abuse substances is also not motivated to plan for his future or even invest in future or even invest in future oriented behaviour.

When this problem surfaces, counselling is main tool that is recommended. Potential asset to counseling, as indicated by Daviss and Diler (2012) is its increased awareness of the future. The young adult under the pressures of life is impelled to withdraw from the present fantasies. In no period of life does one depend so heavily upon the promises of the future than during adolescence. Moshman (2009) also recommends that the importance of capitalizing upon the strength in counseling by working actively with the adolescent to develop a realistic and attractive picture of his own future. It can be inferred through the literature presented here that adolescents who abuse substances have a negative view of their future unlike their counterparts who do not abuse substances. It can also be gathered that this negative nature of future orientation can be addressed by significant others to develop as being positive, detailed and realistic.

\section{References}

Anckarsäter H, Lundström S, Kollberg L,. (2011)The Child and Adolescent Twin Study in Sweden (CATSS). Twin Res Journal; 14:495-508.

Benton, T. and Craib, I. (2011) Philosophy of social science: The philosophical foundations of social thought, 2nd ed., Palgrave Macmillan, New York, NY.

Cano, M. Á., Castillo, L. G., Davis, M. J., López-Arenas, A., Vaquero, J., Thompson, K. V., \& Saldivar, I. M. (2012). Dynamics of Acculturation, Enculturation, and Ethnic Identity: Influence of Psychocultural Constructs on Conscientiousness and Expectations of Higher Education Among Latinos. International Journal for the Advancement of Counseling, 1-11

Carver, C. S., \& Scheier, M. F. (2011). Self-regulation of action and affect. In K. D. Vohs, R. F. Baumeister, K. D. Vohs, R. F. Baumeister (Eds.) Handbook of self-regulation: Research, theory, and applications (2nd ed.) (pp. 3-21). New York, NY US: Guilford Press.

Creswell, J. W. (2012). Qualitative inquiry and research design: Choosing among five traditions (3rd ed.). Thousand Oaks, CA: Sage.

Crockett, L.J., Carlo, G., Wolff, J.M., \& Hope, M. (2011). The role of pubertal development, emotional reactivity, and self-regulation in adolescent 
prosocial behaviours.

Daviss, W.B. \& Diler, R. (2012). Does comorbid depression predictsubsequent adverse life events in youth with Attention-Deficit/Hyperactivity disorder? Journal of Child and Adolescent Psychopharmacology, 22, 65-72.

Donald, D., Lazarus, S., \& Lolwana, P. (2010). Educational Psychology in Social Context.Cape Town: Oxford University Press.

Hamman, D., Gosselin, K., Romano, J., \& Bunuan, R. (2010). Using possible-selves theory to understand the identity development of new teachers. Teaching and Teacher Education, 26(7), 1349-1361.

Horstmanshof, L., \& Zimitat, C. (2007). Future time orientation predicts academic engagement among first-year university students. British Journal of Educational Psychology, 77, 703-718.

Husman, J., \& Shell, D. F. (2008). Beliefs and perceptions about the future: a measurement of future time perspective. Learning and Individual Differences, 18, 166-175.

Kuhn, D. (2008). Formal operations from a twenty-first century perspective. Human Development, 51(1), 48-55.

Lasane, T P \& Jones, J M 1999: Temporal Orientation and Academic Goal Setting: The Mediating Properties of a Motivational Self. Journal of Social Behaviour and Personality, 14 (1), 31-44.

Little, B. R. (2007). Prompt and circumstances: the generative context of personal projects analysis. In B. R. Little, K. Salmena-Aro, \& S. D. Phillips (Eds.), Personal project pursuit: Goals, actions, and human flourishing (pp. 3e49). Mahwah, NJ: Erlbaum.

Manzi, C., Vignoles, V. L., \& Regalia, C. (2010). Accommodating a new identity: Possible selves, identity change and well-being across two lifetransitions. European Journal of Social Psychology, 40(6), 970-984.

Marcia, J. E. (1993). The status of the statuses: Research review. In J. E. Marcia, A.S.Waterman, D. R. Matteson, S. L. Archer, \& J. Orlofsky (Eds.), Ego identity: A handbook for psychosocial research (pp. 22-41). New York: Springer-Verlag.

Markus, H \& Nurius, P. (1996). Possible selves. American Psychologist 41: 954-969.

Massey, E.K., Gebhardt, W.A., \& Garnefski, N. (2008). Adolescent goal content and pursuit: review of the literature from the past 16 years. Developmental Review, 28(4), 421-460.

Norem, J K \& Cantor, N 1996: Anticipatory and post hoc cushioning strategies: Optimism and Defensive pessimism in "risky" situations. Cognitive Therapy Research, 10, 347-362.

Moshman, D. (2009). Adolescence. In U. Muller, J. Carpendale, \& L. Smith (Eds.) The Cambridge Companion to PIAGET (255-269). Cambridge University Press: New York City.

Nurmi, J. E. (1991). How do adolescents see their future? A review of the development of future orientation and planning. Developmental Review,11, 1-59.

Nurmi, J. E. (2005). Thinking about and acting upon the future. In A. Strathman \& J. Joireman (Eds.), Understanding behaviour in the context of time (pp. 31-57). New Jersey: Lawrence Erlbaum Associates Publishers.

Nurmi, J.E. (2004). Socialization and self development: Channeling, selection, adjustment, and reflection. In R. Lerner \& L. Steinberg (Eds.), Handbook of Adolescent Psychology, Second Edition (pp. 85 - 124).New Jersey: Wiley.

Nurmi, J. E., Poole, M.E., \& Seginer, R. (1995).Tracks and transitions-A comparison of adolescent future-oriented goals, explorations, and commitments in Australia, Israel, and Finland. International Journal of Psychology, 30, 3, 355-375.

Nurmi, J. E., Poole, M.\& Kalakoski, V. (1994). Age differences in adolescent future-oriented goals, concerns, and related temporal extension in different socio-cultural contexts. Journal of Youth and Adolescence, 23, 4, 471-487.

Nuttin, J R 1984: (In Oyserman, D E \& Markus, H 1990: Possible Selves and delinquency. Journal of Personality and Social Psychology. 59, 112125).

Robers, S., Zhang, J., Truman, J., \& Snyder, T. D. (2010). Indicators of School Crime and Safety: 2010. USA: US Department of Education.

Romero, A. (2013)"Educational Future Orientation of Middle School Latino Students". Counseling and Psychological Services Dissertations. Paper 87.

Sciarra, D. T., \& Ambrosino, K. E. (2011). Post-secondary expectations and educational attainment. Professional School Counseling, 14(3), 231241.

Seginer, R. (2009). Future orientation: Developmental and ecological perspectives. New York: Springer.

Sheldon, K. M., \& Vansteenkiste, M. (2005). Personal goals and time travel: how are future places visited, and is it worth it? In A. Strathman, \& J. Joireman (Eds.), Understanding behaviour in the context of time: Theory, research and application (pp. 143-163) Mahwah, NJ: Erlbaum.

Sica, L. (2009). Adolescents in different contexts: The exploration of identity through possible selves. Cognition, Brain, Behaviour: An Interdisciplinary Journal, 13(3), 221-252.

Tabachnik, S. E., Miller, R. B., \& Relyea, G. E. (2008). The relationships among students' future oriented goals and subgoals, perceived task instrumentality, and task-oriented self-regulation strategies in an academic environment. Journal of Educational Psychology, 100, 629642.

Vansteenkiste, M., Lens, W., \& Deci, E. L. (2006). Intrinsic versus extrinsic goal-contents in self-determination theory: another look at the quality of academic motivation. Educational Psychologist, 41, 19-31.

Vansteenkiste, M., Sierens, E., Soenens, B., Luyckx, K., \& Lens, W. (2009). Motivational profiles from a self-determination perspective: the quality of motivation matters. Journal of Educational Psychology, 101, 671-688.

Wallentin, F.Y., J€oreskog, K.G. \& Luo, H. (2010). Confirmatory factor analysis of ordinal variables with misspecified models. Structural Equation Modeling: A Mutidisciplinary Journal, 17, 392-423.

Wolman, B. B., (1998). Adolescence: Biological and psychosocial perspectives. West Port, CT: Greenwood Press.

Zhang, L., Karabenick, S. A., Maruno, S., \& Laurermann, F. (2011). Academic delay of gratification and children's study time allocation as a function of proximity to consequential academic goals. Learning and Instruction, 21(1), 77-94. 